\title{
INTRODUCCIÓN.
}

\section{REGIONES FRONTERIZAS ENTRE DESPLAZAMIENTO Y EXCEPCIONALIDAD}

\author{
Introduction. Border Regions Between Displacement \\ and Exceptionality
}

\section{ELENA RITONDALE}

Universidad Autónoma de Barcelona (España)

elena.ritondale@uab.cat

ORCID: https://orcid.org/ 0000-0003-3014-9642

ROXANA RODRÍGUEZ ORTIZ

Universidad Autónoma de la Ciudad de México (México)

roxana.rodriguez@uacm.edu.mx

ORCID: https://orcid.org/0000-0002-6281-2835

$\mathrm{Al}$ momento de decidirnos por el título de este dossier, "Regiones fronterizas entre desplazamientos y excepcionalidad", llevábamos pocos meses de haber iniciado la pandemia provocada por el virus covid-19. Las fronteras en prácticamente todo el mundo se estaban cerrando al tránsito de personas, no así de mercancías y capitales. Las regiones fronterizas en la mayoría de los continentes donde llevamos décadas observando diferentes políticas de control migratorio y de externalizaciónborderización fronteriza no estuvieron exentas de este cierre salvo en contados casos, como la frontera México-Guatemala. En la Unión Europea, Estados Unidos, lo mismo que en Australia, y otros países de América, el efecto del cierre fronterizo fue inminente. De ahí que hayamos escogido dos conceptos presentes en la literatura contemporánea de los Estudios Críticos de las Fronteras (Critical Border Studies): desplazamiento y excepcionalidad (Derrida, 2005), para dar cuenta precisamente de lo que nos estaba tocando vivir en este incipiente siglo XXI.

El cierre de fronteras, contrario a lo que muchos gobiernos esperaban, no significó la disminución en el desplazamiento de la movilidad humana, pues las personas han seguido migrando y 
solicitando refugio en los diferentes continentes; mientras que al inicio de la pandemia autores como Agamben (2020) se pronunciaban en contra del estado de excepción al que estaban convocando los propios gobiernos en nombre de la soberanía, de la seguridad nacional y de la seguridad sanitaria.1 Un discurso que evidentemente siempre ha estado presente en el resguardo de la soberanía que en términos derridianos se explica como la espera condicionada a la excepcionalidad de la soberanía de quien ostenta la fuerza de la ley (Rodríguez, 2020).

A partir del conocimiento situado de los textos que presentamos ahora podemos dar cuenta de esos desplazamientos disciplinares observados en los Estudios Críticos de las Fronteras, y que han modificado su perspectiva de análisis, al pasar de lo meramente sociológico, demográfico y antropológico a integrar en sus metodologías la teoría literaria, los estudios culturales, la autoetnografía, de la mano de apuestas epistemológicas que incluyen lo que algunos autores han denominado el giro ontológico, la estética, la ética y obviamente el derecho y la política.

Consideramos que los Critical Studies son una vertiente epistemológica que deviene de la deconstrucción y del trabajo en particular hecho por Jacques Derrida en tres niveles que mencionaremos sintéticamente: 1) El estilo de escritura que transita entre lo literario-poético-filosóficopolítico-autobiográfico (que también — hay que decir- ha sido muy cuestionado, principalmente por los filósofos analíticos) y abre la puerta a esa noción de la différance (lo que difiere, la diferencia) en la escritura académica mediante la recuperación de las figuras retóricas, especialmente la metáfora, la metonimia, la elipsis. 2) Evidentemente la práctica de la deconstrucción como una experiencia de lo imposible, que toma forma en la aporía: "En general, la deconstrucción se practica con arreglo a dos estilos injertados uno en el otro por aquella. Uno tiene el aire demostrativo y aparentemente nohistórico de las paradojas lógico-formales. El otro, más histórico o amnésico, parece proceder mediante lecturas de textos, interpretaciones minuciosas y genealogías" (Derrida, 2010: 49). 3) La diseminación que deja "fuera del texto" la axiomatización binómica existente en la cultura occidental: "La diseminación abre, sin fin, esta ruptura de la escritura que ya no se deja recoser, el lugar en que ni el sentido, aunque fuese plural, ni ninguna forma de presencia sujeta ya la huella" (Derrida, 1997: 41).

Entre estos dos conceptos, el desplazamiento y la excepcionalidad, tensamos los puntos circundantes de la reflexión subjetiva, corporizada, política, estética, ética, performativa de las narrativas fronterizas que nos interesaba recuperar para el presente dossier. Y son precisamente estos tres niveles en los que nos hemos interesado al proponer la tensión que observamos en las regiones fronterizas, en los desplazamientos que no cesarán como tampoco en la excepcionalidad condicionada de los gobiernos para reprimirlos.

Los artículos incluidos en este dossier muestran una variedad de acercamientos y de enfoques temáticos. No obstante, creemos que comparten ciertos rasgos que permiten incluirlos en tres grandes bloques. Consideramos que —en distintos niveles - los textos de Camille Dasseleer, Anne Brüske e Inéz Maria Wellner, Carolyn Wolfenzon y el de María Eugenia Argañaraz se pueden leer desde la noción de la différance, ya que interrogan sus respectivos objetos de estudio haciendo hincapié —entre otras cosas - en el fluir de dimensiones ficcionales y no ficcionales, artísticas y políticas.

En particular, Camille Dasseleer, en su artículo dedicado al multilingüismo decolonial en obras de Cecilia Vicuña y Pilar Rodríguez Aranda, propone un análisis comparativo del video poema Ella es frontera/Border She Is (1996-2001), de la primera autora, y del poema "Instan" (2002) escrito e interpretado por la segunda. A partir de las teorías de la socióloga boliviana Silvia Rivera Cusicanqui y

\footnotetext{
1 Por otro lado, aunque no se pueda ahondar aquí en este tema, la posición del filósofo italiano fue objeto también de criticas y polémicas, en particular en Italia, donde la pandemia ha causado la muerte de más de 100.000 víctimas hasta la fecha. Tras su posicionamiento, empezó un debate que involucró, entre otros, a Marco Revelli, el colectivo Wu Ming, Davide Grasso y Paolo Ercolani y muchos otros.
} 
de la filósofa chicana Gloria Anzaldúa, Dasseleer enfoca la investigación en el uso del multilingüismo por parte de ambas autoras. La situación fronteriza de las identidades mestizas en el continente americano se puede leer, de acuerdo con Dasseleer, en el nexo entre el tipo de hibridez formal traducida por la transgresión heterolingüística y una reflexión política, con lo cual se sugieren caminos que cuestionan la pugna entre compromiso y experimentación formal, entre vidas desplazadas y estética. A partir del concepto aymara de lo ch'ixi, se articulan nuevas representaciones de la condición interseccional.

A la teorización del concepto de frontera elaborada por Gloria Anzaldúa es dedicado el trabajo de Anne Brüske e Inéz Maria Wellner. Las dos autoras re-leen Borderlands/La frontera. The New Mestiza enfocándose en las dinámicas fronterizas que se producen en el texto entre distintos modos de expresión: los genéricos y los perceptivos. Al recurrir a la técnica del close reading y a partir de la que definen una versión descolonizada del modelo fenomenológico de Henri Lefebvre (1974), Brüske y Wellner iluminan la importancia de la corporalidad del sujeto en Borderlands, que, además, crea un espacio de comunicación entre el texto y su audiencia. Justamente su complejidad —en la que se articulan dimensiones espaciotemporales, pero también lingüísticas, culturales y sociales múltipleshace que sea posible acercarse nuevamente a esta obra ya canonizada y, de alguna forma, "absorbida" por la academia de EE.UU., de acuerdo con la propuesta de las dos investigadoras.

Carolyn Wolfenzon ilumina a su vez la porosidad de la frontera entre niveles distintos lingüístico, temporal y material-, en su artículo dedicado a Loxoro (2012) de Claudia Llosa. En la lectura que brinda del trabajo de la directora, Wolfenzon nos lleva a un territorio no demarcado físicamente, pero donde se imponen límites precisos —en la forma de vivir el espacio-tiempo, pero también el lenguaje — vinculados con la identidad de las protagonistas, mujeres transexuales de Lima. Wolfenzon observa cómo la frontera, herramienta de epistemologías hegemónicas que encasillan y separan cualquier elemento definitorio de la identidad, en Loxoro divide y clasifica a los sujetos según el género, la lengua y la propia experiencia subjetiva del cuerpo. Al hacer referencia a una idea de Marjorie Garber, propone que los cuerpos transexuales producen ansiedad en una sociedad dominada por lógicas de género hegemónicas, porque cuestionan la artificialidad binaria con la que se ordena el mundo.

María Eugenia Argañaraz, por su parte, investiga el concepto de "familia revolucionaria" en obras ambientadas durante la dictadura argentina. A través de una lectura de La casa de los conejos (2008) de Laura Alcoba y de la película Infancia clandestina (2012) de Benjamín Ávila, Argañaraz ilumina la presencia de narraciones que se desarrollan a partir de la mirada de los niños, vuelta pilar de una memoria familiar. Dicha mirada, a la vez, de acuerdo con la lectura de la autora, cuestiona la visión hegemónica tanto de la infancia como de la maternidad. En tanto define la condición de estos jóvenes protagonistas como una "infancia fronteriza", Argañaraz deconstruye los estereotipos de niñez y de maternidad, al poner ambas en un contexto de violencia política.

Otros artículos de este dossier se pueden leer, proponemos, en diálogo con el concepto de aporía. Se trata de los trabajos de Felipe Oliver Fuentes, Josefa Fernández Zambudio, Juan Pablo Marcoleta y Bernat Garí Barceló. Felipe Oliver Fuentes analiza tres ficciones españolas ambientadas en Campo de Gibraltar, gracias a lo cual permite incluir en este dossier una de las fronteras más complejas del mundo: la situada entre España y Marruecos. Para investigar algunas problemáticas fronterizas concretas - en particular la demarcación por el exterior y por "el interior", y los límites tanto de las dinámicas económicas como de la ley-, Fuentes elije tres obras que comparten el formato de la novela criminal: La reina del sur, Lejos del corazón y Moroloco. Gracias a ellas, el autor subraya las contradicciones del contexto objeto y telón de fondo de la narración, y destaca cómo la búsqueda de una lógica que pueda volver inteligibles ciertos acontecimientos — característica del género policial— se 
vuelve imposible en el entorno fronterizo entre Europa y África, en cuanto arrojan una luz de esta forma sobre las múltiples contradicciones que aquí se producen.

Josefa Fernández Zambudio mueve el estudio de la "frontera" al espacio discursivo, al investigar el desplazamiento de algunos mitos femeninos en poemas de Rosario Castellanos. Enfocada en los términos específicos que remiten a la idea de límite en la obra de la autora, analiza la dialéctica producida entre la tradición y la búsqueda de patrones de identidad femenina.

También Juan Pablo Marcoleta Hardessen reflexiona sobre la articulación entre frontera y condición de género. En su artículo dedicado a la pampa en la obra de Rivera Letelier, ilumina la forma en que este autor narra el norte chileno y las pampas como lugares de subalternidad. En particular, Marcoleta analiza la condición de las mujeres en las obras escogidas, a partir de su posición en las dinámicas de poder e interrogándose sobre su devenir sujetos de la historia.

Bernat Garí Barceló dedica su texto a la obra de la escritora mexicana Valeria Luiselli; sin embargo, e innovando en este sentido el panorama de estudios críticos sobre la autora, no se centra en la representación de la frontera en una de sus obras concretas, sino que traza una tendencia general de su producción. De acuerdo con Garí, el conjunto de las narraciones de Luiselli muestra un denominador común: la sujeción de la escritura a la que define como una "lógica móvil" que muestra una transformación, en el corpus estudiado, desde un "movimiento solitario" en las primeras obras a otro movimiento, más amplio y colectivo, que tiene en el tema de la acogida y de los refugiados su cumbre.

El tercer grupo de textos se puede leer, de acuerdo con nuestra propuesta, desde la categoría de la diseminación que, tal como se ha indicado arriba, excluye del texto la axiomatización binómica típica del pensamiento occidental. En este bloque y por razones distintas incluimos los artículos de Francisco Javier Hernández Quezada y Laura Díaz, así como la conversación con un grupo de artistas y performers de la ciudad de Tijuana sobre la "práctica" de la frontera "en" y "desde" el arte y la creación. Tanto el texto de Francisco Javier Hernández Quezada como el de Laura Díaz nos llevan a la frontera entre Tijuana y California; ahora bien, mientras que el primero se centra en la temática del desplazamiento relatada por escritores de la ciudad mexicana ya definida por García Canclini como el laboratorio de la posmodernidad, y ahonda en un yo literario-bajacaliforniano-tijuanense y en sus implicaciones en la escritura, Laura Díaz brinda una reflexión de tipo estético cuyo centro es el concepto de lo "hipofronterizo", la dialéctica entre aceptación y rechazo de la temática vinculada con el espacio liminal en el mundo de la creación visual en la ciudad de Tijuana.

Por último, este dossier también da cuenta de las publicaciones que creemos relevantes considerar para ahondar en los Estudios Críticos de Frontera. La primera de ellas, realizada por Andrea Padilla, hace referencia al libro titulado Debating and defining borders: Philosophical and theoretical perspectives, editado por Anthony Cooper y Søren Tinning y publicado por Routledge en el marco de la serie de la editorial Borderland Studies a principios del 2020. Una compilación de textos que consideramos los más representativos de esta vertiente de los estudios fronterizos a nivel internacional. Por su parte, Guillermo Yrizar recupera la obra de la historiadora Adam Goodman, titulada The Deportation Machine: America's long history of expelling immigrants (2020), para enfatizar la precaria situación de las personas migrantes. Alude a la metáfora que Adorno y Horkheimer utilizaron para referirse a la razón instrumental: echar a andar la maquinaria, como se observa en las diferentes políticas migratorias en todo el mundo.

Lo rápido que han crecido los análisis hipertextualizados e intertextuales en los Critical Border Studies permite lecturas disímiles de eso que en español entendemos genéricamente como fronteras y que en otras lenguas tiene un juego más sutil y que es importante considerar en las traducciones ontológicas de la frontera en sí, como hemos querido dar cuenta en este dossier. 


\section{Bibliografía}

AgAmBEN, Giorgio (2020), "Lo stato d'eccezione provocato da un'emergenza immotivata", Il Manifesto. Consultado en: https://ilmanifesto.it/lo-stato-deccezione-provocato-da-unemergenza-immotivata/ (30/06/2021).

DERridA, Jacques (2005 [2003]), Canallas. Dos ensayos sobre la razón. De Perreti, Cristina (trad.). Madrid, Trotta.

Grasso, Davide (2020), "Agamben, il coronavirus e lo stato di eccezione”, Minimaetmoralia.it. Consultado en: https://www.minimaetmoralia.it/wp/approfondimenti/agamben-coronavirus-lo-eccezione/ $(30 / 06 / 2021)$.

Rodríguez OrTIZ, Roxana (2020), Migración cero. Reterritorializar la condición de refugiado en México. México, Bajo Tierra.

Wu, Ming (2020), "Diario virale/3. Contro chi sminuisce l'emergenza", Giap. Consultado en: https://www.wumingfoundation.com/giap/2020/03/diario-virale-3/ (30/06/2021). 